\title{
Electronic Fans: A pathogen reservoir and potential cross- contamination source
}

\author{
Vance Bergeron ${ }^{1 *}$, Amine Metahni ${ }^{1}$ and Francis Derouin ${ }^{2}$ \\ ${ }^{1}$ CNRS UMR 5672, Ecole Normale Supérieure de Lyon, 46 allée d'Italie, 69007, Lyon, France \\ ${ }^{2}$ Laboratory of Parasitology-Mycology, Saint-Louis hospital, Assistance Publique-Hôpitaux de Paris \\ and University Paris, Diderot, 111 ave Claude Vellefaux, 75010, Paris, France
}

Received: 23 September, 2020

Accepted: 14 October, 2020

Published: 15 October, 2020

*Corresponding author: Dr. Vance Bergeron, CNRS UMR 5672, Ecole Normale Supérieure de Lyon, 46 allée d'Italie, 69007, Lyon, France, Tel: +33(0)472728000; E-mail : vance.bergeron@ens-lyon.fr

Keywords: Cross-contamination; Ventilation fans; Aspergillus

https://www.peertechz.com

\section{Check for updates}

\section{Abstract}

With the recent outbreak of COVID-19 the concern for airborne pathogens has increased. It is clear now that taking preventative measures such as wearing masks and social distancing are important to abate the spread and transmission of airborne pathogens. It is also equally important to identify and minimize the different sources of both direct and cross-contamination. Here we identify one source that has thus far not been considered: electronic fans used to cool the electronic components in equipment used throughout our daily lives; computers, hospital instruments, and significantly airborne samplers. Airborne samplers used to evaluate airborne pathogens must have their fan air exiting the device filtered, otherwise the device itself can be an important source as different location are sampled, moving the pathogen load from one location to another.

\section{Introduction}

Computer keyboards are a well-recognized reservoir for infectious pathogens, and a potential vector for crosscontamination [1-4]. This concern has led to necessary measures for the cleansing and disinfection of keyboards, barrier precautions and the reinforcing of hand-hygiene compliance [4]. We have identified similar, related concerns for ventilation fans in computers, electronic equipment and instruments as a source of cross-contamination. Controlled laboratory experiments show that airborne fungal spores deposit onto the blades of these fans and can subsequently be released once moved to a new location. This phenomenon appears to be grossly overlooked and could have substantial consequences, particularly in high infection-risk areas, like hospitals and other similar environments.

\section{Methods}

In our work we have focused on fungal spores, which are ubiquitously found in the environment, and known to be an important contamination risk for immunocompromised patients. Furthermore these opportunistic pathogens can remain viable on formites for months in relatively dry locations. Our systematic testing was performed with Aspergillus niger fungal spores, suspended in a $1 \mathrm{~m}^{3}$ hermetically closed chamber. Ventilation fans, removed from electronic equipment (a computer and printer) were cleaned, disinfected, and placed in the center of the chamber, after first contact sampling their blades for control. A. niger was then aerosolized inside the chamber by blowing compressed air over a fully colonized petri dish. The fans were then activated and run at their nominal speed for two hours. Afterwards the chamber was flushed and the fans were removed to sample their blade surfaces. Ten independent tests confirmed that an abundant amount of A. niger is deposited onto the fans blades during expose to the aerosol in the chamber. Following each exposure test the contaminated fans were returned to a freshly cleaned chamber and again activated. Subsequent air samples within the chamber, while the fans were running, systematically established that spores left on the fan blades were released into the air.

To obtain surface samples we used standardized procedures (see: Detection and enumeration of bacteria in swabs and other environmental samples National Infection Service Food Water and Environmental Microbiology Standard, Document number FNES4 Version number 4 Effective Date 23.05.17). Our sampling swabs 
were purchased from Aldrich chemicals; WHAWB100035 Whatman ${ }^{\circledR}$ FTA $^{\circledR}$ collection products. The Agar plates were made from Agar powder purchased from Millipore (ref . 05040). Culture identification was analyzed and reported by the Microbiology department from Laboratory of ParasitologyMycology, Saint-Louis hospital, Assistance Publique-Hôpitaux de Paris.

\section{Results and conclusions}

To understand the potential for cross-contamination in a hospital environment, a survey was conducted in two different hospital wards that housed immunocompromised patients. Surface samples from fan blades were taken at random from four different laptop computers, three standing fans, four floor-standing computers and two printers. Fungal spores were found on every sampled fan blade and over eleven different species were identified (Table 1). These findings further confirm that fan blades in electronic instruments are a major reservoir for pathogens and raise serious concerns over their potential as a cross-contamination source.

Table 1: Summary of fungal colony counts from swabbed surface sampling of device fan blades in two hospital wards. Two samples from each laptop and one from the other devices are reported. Fungal colonies were cultivated from every sampled blade and over eleven different species were found. Values are reported in Colony Forming Units (CFU)

\begin{tabular}{|c|c|c|c|c|c|c|c|c|c|c|c|c|c|c|c|c|c|c|}
\hline Service/Ward & \multicolumn{12}{|c|}{ Pneumology } & \multicolumn{6}{|c|}{ Bone marrow transplant unit } \\
\hline & \multicolumn{8}{|c|}{ Laptops } & \multicolumn{4}{|c|}{ Standing Fans } & \multicolumn{4}{|c|}{ Desktop Computers } & \multicolumn{2}{|c|}{ Printers } \\
\hline Device I.D. & \multicolumn{2}{|c|}{ L1 } & \multicolumn{2}{|c|}{ L2 } & \multicolumn{2}{|c|}{ L3 } & \multicolumn{2}{|c|}{ L4 } & SF1 & SF2 & SF3 & SF4 & $D C 1$ & $D C 2$ & $D C 3$ & $D C 4$ & P1 & $P 2$ \\
\hline Alternaria $s p$. & - & 4 & 6 & 10 & - & - & - & - & - & - & - & $>20$ & - & - & - & - & - & - \\
\hline Aspergillus flavus & 2 & 7 & 1 & - & 1 & - & - & 2 & 6 & 7 & - & 2 & - & - & - & - & - & - \\
\hline Aspergillus fumigatus & 16 & 11 & 1 & 10 & 8 & 10 & - & 15 & - & 3 & 2 & - & - & - & - & - & - & - \\
\hline Aspergillus niger & 3 & 12 & 5 & 6 & 3 & 3 & 3 & 9 & $>20$ & 9 & 5 & 3 & - & - & 1 & - & - & - \\
\hline $\begin{array}{c}\text { Aspergillus section } \\
\text { Usti }\end{array}$ & - & - & - & - & 3 & - & - & 5 & - & - & - & - & - & 2 & - & - & - & - \\
\hline Trichoderma sp. & - & - & - & - & - & - & - & - & - & - & - & 2 & - & - & - & - & - & - \\
\hline Chrysonilia sitophila & - & - & - & - & - & - & layer & - & layer & - & - & - & - & - & - & - & layer & - \\
\hline Mucor sp. & layer & - & layer & - & - & - & - & - & - & - & layer & - & - & - & - & - & - & - \\
\hline Paecilomyces sp. & - & - & - & - & - & - & - & - & - & - & - & - & $>20$ & $>20$ & $>20$ & $>20$ & - & - \\
\hline Penicilium sp. & - & - & $>20$ & $>20$ & 17 & 18 & 8 & - & & 15 & 7 & 12 & - & - & - & - & - & - \\
\hline Unidentified & $>20$ & $>20$ & 10 & 12 & $>20$ & 10 & $>20$ & $>20$ & $>20$ & $>20$ & 10 & $>20$ & - & 1 & - & 1 & 11 & 1 \\
\hline
\end{tabular}

\section{References}

1. Neely AN, Maley MP, Warden GD (1999) Computer Keyboards as Reservoirs for Acinetobacter baumannii in a Burn Hospital. Clin Infect Dis 29: 1358-1360. Link: https://bit.ly/3jZ4xAv

2. Hartman B, Benson M, Junger A, Quinzio L, Rohri R, et al. (2004) Compute Keyboard and Mouse as a Reservoir of Pathogens in the Intensive Care Unit. J Clin Monit Comput 18: 7-12. Link: https://bit.ly/2SSaKT9
3. Achieng AA, Nkechi NN (2010) Nosocomial Infections Transmitted via computers: A Literature Review. Thesis Degree Program in Nursing, Laurea University of Applied Sciences. Link: https://bit.ly/3iZ9rML

4. Rutala WA, White MS, Gergen MF, Weber DJ (2006) Bacterial contamination of keyboards: Efficacy and functional impact of disinfectants. Infect Control Hosp Epidemiol 27: 372-377. Link: https://bit.ly/33UP6ni

Copyright: ( 2020 Bergeron V, et al. This is an open-access article distributed under the terms of the Creative Commons Attribution License, which permits unrestricted use, distribution, and reproduction in any medium, provided the original author and source are credited. 